\title{
The clinical and radiographic characteristics of avascular necrosis after pediatric femoral neck fracture: a systematic review and retrospective study of 115 patients
}

Pengfei Xin ${ }^{1,2}$, Yonggang Tu ${ }^{1,3}$, Zhinan Hong ${ }^{4}$, Fan Yang ${ }^{1,2}$, Fengxiang Pang ${ }^{1,2}$, Qiushi Wei ${ }^{4}$, Wei He ${ }^{4^{*}}$ and Ziqi $\mathrm{Li}^{1,4^{*}}$

\begin{abstract}
Background: Avascular necrosis (AVN) after pediatric femoral neck fracture (PFNF) showed poor prognosis, but its clinical and radiographic characteristics remained unclear.

Methods: A systematic review and a retrospective study were performed to evaluate the clinical and radiographic characteristics of patients with AVN after PFNF.

Results: A total of 686 patients with PFNF and 203 patients with AVN from 21 articles were analyzed. Ratliff's classification was used in 178 patients, with types I, II, and III AVN accounting for 58.4\%, 25.3\%, and 16.3\%, respectively. Ratliff's assessment was used in 147 patients, of whom $88.4 \%$ had an unsatisfactory prognosis. In retrospective study, 115 patients with a mean age of $13.6 \pm 2.0$ years were included. The mean interval between AVN and PFNF was $13.7 \pm 9.5$ months. At the time of diagnosis, $59.1 \%$ cases were symptomatic and $65.2 \%$ progressed to collapsed stage. Fifty (43.5\%), 61 (53.0\%), and 4 patients (3.5\%) were defined as types I, II, and III , respectively, via Ratliff's classification. Thirteen (11.3\%), 40 (34.8\%), and 62 patients (53.9\%) showed types A/B, C1, and C2 disease, respectively, via the JIC classification. Multivariate analysis demonstrated a strong relation between collapsed stage and symptomatic cases $(\mathrm{OR}=6.25,95 \% \mathrm{Cl}=2.39-16.36)$ and $\mathrm{JIC}$ classification $(\mathrm{OR}=3.41,95 \% \mathrm{Cl}=$ 1.62-7.17).

Conclusion: AVN after PFNF showed a tendency toward extensive necrotic lesions, presumably resulting in a rapid progression of femoral head collapse. And the symptoms and the JIC classification are other two risk factors of collapse progression.
\end{abstract}

Keywords: Avascular necrosis, Femoral neck fractures, Child, Adolescent

\footnotetext{
*Correspondence: hw13802516062@126.com; ionsev0214@126.com

${ }^{4}$ Department of Joint Surgery, The Third Affiliated Hospital of Guangzhou University of Chinese Medicine, Guangzhou 510405, China

${ }^{1}$ The First Clinical Medical School, Guangzhou University of Chinese Medicine, Jichang Road 12\#, District Baiyun, Guangzhou, Guangdong, China Full list of author information is available at the end of the article
}

(c) The Author(s). 2020 Open Access This article is licensed under a Creative Commons Attribution 4.0 International License, which permits use, sharing, adaptation, distribution and reproduction in any medium or format, as long as you give appropriate credit to the original author(s) and the source, provide a link to the Creative Commons licence, and indicate if changes were made. The images or other third party material in this article are included in the article's Creative Commons licence, unless indicated otherwise in a credit line to the material. If material is not included in the article's Creative Commons licence and your intended use is not permitted by statutory regulation or exceeds the permitted use, you will need to obtain permission directly from the copyright holder. To view a copy of this licence, visit http://creativecommons.org/licenses/by/4.0/ The Creative Commons Public Domain Dedication waiver (http://creativecommons.org/publicdomain/zero/1.0/) applies to the data made available in this article, unless otherwise stated in a credit line to the data. 


\section{Introduction}

Pediatric femoral neck fractures (PFNFs) are rare but devastating injuries that are mostly induced by highenergy trauma in children and adolescents, with an incidence of less than 1\% [1,2]. Avascular necrosis (AVN) is the most common complication that occurs after PFNF, resulting in poor prognosis that is debilitating and potentially disabling in young populations. Accumulating evidence-based medical research has confirmed the high incidence of AVN after PFNF. For example, an average incidence of $23.5 \%$ was reported by a meta-analysis that included 30 studies and 935 patients in 2013 [3]. A similar outcome, an incidence of $24.5 \%$, was confirmed repeatedly in a review of 239 cases of PFNF in 2019 [4]. However, the clinical and radiographic characteristics of AVN after PFNF remain foreign to most orthopedic surgeons because of the rare incidence of primary injury.

To the best of our knowledge, a handful of studies have specifically described the characteristics of AVN after PFNF. In 1962, Ratliff et al. [2] first described three patterns of AVN after PFNF according to a review of 29 cases: the highest incidence was of AVN occupying the total head (type I, 15 cases), followed by partial necrosis of the epiphysis (type II, 7 cases) and necrosis between the epiphyseal plate and the fracture line (type III, 7 cases). Numerous subsequent studies adapted this criterion (Table 1); however, the limited sample size of enrolled patients was insufficient for demonstrating the prognostic value of Ratliff's classification. In addition, few studies have confirmed the relationship between the prognosis of AVN after PFNF and other recognized prognostic factors for most types of AVN, including hip symptoms, the presence of collapse at diagnosis, and the location of the lesion $[25,26]$.

As we believe, a specific description of the clinical and radiographic characteristics of AVN after PFNF is beneficial for understanding the potential disease progression and managing targeted treatments. Considering the low incidence of PFNF, we aimed to elucidate the clinical and radiographic characteristics of AVN after PFNF via

Table 1 The outcomes of AVN after PFNF in the published literature as described by the Ratliff classification system and assessment

\begin{tabular}{|c|c|c|c|c|c|c|c|c|c|}
\hline \multirow[t]{2}{*}{ Authors } & \multirow[t]{2}{*}{ Year } & \multirow[t]{2}{*}{ Patients } & \multirow{2}{*}{$\begin{array}{l}\text { Mean age, } \\
\text { years } \\
\text { (range) }\end{array}$} & \multirow[t]{2}{*}{ AVN } & \multicolumn{3}{|c|}{ Ratliff classification $^{*}$} & \multicolumn{2}{|c|}{ Ratliff assessment $^{* *}$} \\
\hline & & & & & $\mathrm{I}$ & II & III & Satisfied & Unsatisfied \\
\hline Stone et al. [5] & 2015 & 22 & $11.0(4.5-17.4)$ & 8 & 5 & 2 & 1 & 3 & 5 \\
\hline Panigrahi et al. [6] & 2015 & 28 & $10.5(4-15)$ & 4 & 0 & 2 & 2 & NA & NA \\
\hline Bukva et al. [7] & 2015 & 28 & $10.7(4-14)$ & 11 & 6 & 3 & 2 & NA & NA \\
\hline Hadju et al. [8] & 2011 & 8 & $11.6(3-15)$ & 1 & 0 & 1 & 0 & NA & NA \\
\hline Bali et al. [9] & 2011 & 36 & $10.0(3-16)$ & 7 & 6 & 1 & 0 & 0 & 7 \\
\hline Nayeemuddin et al. [10] & 2009 & 14 & $10.0(6-14)$ & 1 & 1 & 0 & 0 & 0 & 1 \\
\hline Inan et al. [11] & 2009 & 39 & $11.1(4-16)$ & 11 & 8 & 1 & 2 & 1 & 10 \\
\hline Varshney et al. [12] & 2009 & 21 & $11.8(5-15)$ & 3 & 1 & 2 & 0 & NA & NA \\
\hline Dhammi et al. [13] & 2005 & 26 & $10.8(3-17)$ & 4 & NA & NA & NA & 0 & 4 \\
\hline Togrul et al. [14] & 2005 & 61 & $10.2(2-14)$ & 9 & 8 & 1 & 0 & NA & NA \\
\hline Flynn et al. [15] & 2002 & 18 & $8.0(2-13)$ & 1 & 0 & 1 & 0 & NA & NA \\
\hline Bagatur et al. [16] & 2002 & 17 & $11.0(7-14)$ & 9 & 4 & 2 & 3 & 0 & 9 \\
\hline Mirdad et al. [17] & 2002 & 14 & $9.1(4-16)$ & 7 & 4 & 3 & 0 & NA & NA \\
\hline Morsy et al. [18] & 2001 & 53 & $10.2(3-16)$ & 21 & NA & NA & NA & 0 & 21 \\
\hline Ng et al. [19] & 1996 & 32 & $9.5(\mathrm{NA})$ & 9 & 7 & 1 & 1 & NA & NA \\
\hline Forlin et al. [20] & 1992 & 16 & $11.7(4.6-16)$ & 14 & 5 & 5 & 4 & 2 & 12 \\
\hline Canale et al. [21] & 1977 & 60 & $9.7(0.5-17)$ & 26 & 21 & 1 & 4 & 1 & 25 \\
\hline Chong et al. [22] & 1975 & 20 & NA (5-19) & 10 & 5 & 5 & 0 & 2 & 8 \\
\hline Zolczer et al. [23] & 1972 & 27 & NA (13-19) & 7 & 2 & 5 & 0 & 5 & 2 \\
\hline Lam et al. [24] & 1971 & 75 & $N A(\leqq 17)$ & 11 & 6 & 2 & 3 & NA & NA \\
\hline Ratliff [2] & 1962 & 71 & $\mathrm{NA}(<17)$ & 29 & 15 & 7 & 7 & 3 & 26 \\
\hline Total & & 686 & & 203 & 104 & 45 & 29 & 17 & 130 \\
\hline Percentage & & & & $29.6 \%$ & $58.4 \%$ & $25.3 \%$ & $16.3 \%$ & $11.6 \%$ & $88.4 \%$ \\
\hline
\end{tabular}

AVN avascular necrosis, NA missing value/not clear

${ }^{*}$ Classification of avascular necrosis as proposed by Ratliff

**Classification of final result according to Ratliff 
(1) a systematic review of the literature since 1962 and (2) a retrospective cross-sectional study based on the clinical and radiographic data from a single center, with a hypothesis that AVN after PFNF might be a rapidly progressing disease with a high risk of femoral head collapse, very likely resulting from its tendency to extensively involve necrotic lesions.

\section{Methods}

\section{Systematic review}

We searched PubMed, Embase, and Web of Science databases with a computer. The literature on osteonecrosis after fracture of the femoral neck in pediatric populations published from January 1960 to November 2019 was comprehensively searched, and the following key words were used: "adolescent" and "teen" and "teenager" and "youths" as well as "femur neck fracture", "femoral neck fracture", "avascular necrosis of the femoral head", "ischemic necrosis of the femoral head", "aseptic necrosis of the femoral head", and "femoral head necrosis", etc. The language was limited to English (see Additional file 1 for the details of the search). In addition, we searched the missing documents from the references, which were retrieved by hand.

\section{Selection criteria}

The inclusion criteria were as follows: (1) age was less than 19 years; (2) a definite history of femoral neck fractures was confirmed by imaging; (3) complications including avascular necrosis were described; and (4) the Ratliff classification was used to assess the degree of avascular necrosis, or the prognosis of patients with avascular necrosis was assessed by the Ratliff criteria [2], and the corresponding data were recorded in detail. The exclusion criteria were as follows: (1) AVN after femoral neck fracture was excluded in adults; (2) literature with incomplete Ratliff classification and prognostic data was excluded; and (3) single case reports and reviews were excluded.

\section{Literature screening and data extraction}

The two authors (Pengfei Xin and Ziqi Li) independently evaluated the retrieved articles by reading the title and abstract and evaluated all the articles that might have met the requirements by obtaining the full text. Any differences between the two authors were settled through discussion. The data extracted from the articles that met the requirements included the following: the total number of patients, age of patients, number of patients with avascular necrosis, degree of avascular necrosis, and final prognosis of patients with avascular necrosis.

The degree of necrosis of the femoral head was assessed using the Ratliff classification: type I-diffuse increases in density of the femoral head accompanied by complete collapse of the epiphysis; type II-partial head involvement with accompanying slight epiphyseal collapse and osteonecrosis; and type III-areas of avascular necrosis, with the range of necrosis usually limited to between the epiphyseal and fracture lines. The data regarding types I, II, and III necrosis were extracted retrospectively. Ratliff's assessment was used to evaluate the prognosis of osteonecrosis patients from both imaging and clinical aspects. The score of good indicated a satisfactory prognostic effect, while a score of poor indicated an unsatisfactory prognostic effect (Table 2). The data regarding satisfactory and unsatisfactory prognoses were extracted retrospectively.

\section{Retrospective study}

After the approval of the Ethics Committee, a retrospective observational study was conducted based on hospitalized patients and outpatients with AVN after PFNF in our institute from January 2000 to January 2018, according to the following inclusion criteria: (1)

Table 2 Classification and prognostic assessment system of avascular necrosis

\begin{tabular}{|c|c|}
\hline Types & The evaluation index \\
\hline \multicolumn{2}{|c|}{ Ratliff's classification of avascular necrosis (AVN) } \\
\hline Type I & Diffuse density increases in the femoral head accompanied by complete collapse of the epiphysis \\
\hline Type $\|$ & Partial head involvement with slight accompanying epiphyseal collapse and osteonecrosis \\
\hline Type III & $\begin{array}{l}\text { Areas of avascular necrosis, with the range of necrosis usually limited to between the epiphyseal } \\
\text { and fracture lines }\end{array}$ \\
\hline \multicolumn{2}{|c|}{ Ratliff system of clinical and radiographic assessment } \\
\hline \multirow[t]{2}{*}{ Good } & Clinical: no pain, normal or slightly limited hip movement, normal daily activity \\
\hline & Radiographic: normal or mild deformity of the femoral neck \\
\hline \multirow[t]{2}{*}{ Fair } & Clinical: occasional pain, limited hip movement less than 50\%, normal daily activity \\
\hline & Radiographic: severe deformation of the femoral neck and mild femoral head necrosis \\
\hline \multirow[t]{2}{*}{ Poor } & Clinical: persistent pain, limited hip movement by more than 50\%, and limited daily activity \\
\hline & Radiographic: severe femoral head necrosis, degenerative arthritis, arthrodesis \\
\hline
\end{tabular}


participants diagnosed with AVN as a complication of a previous fracture of the femoral neck; (2) patients with no history of corticosteroid administration or alcohol abuse; (3) patients aged less than 17 years when the fracture occurred; (4) patients with no other complications from femoral neck fractures, such as nonunion or infection, or from other diseases, such as dysplasia of the hip joint or rheumatoid arthritis; and (5) patients with complete medical records or radiographic data.

The extracted data consisted of the medical record data and radiographic data. We found the medical records and extracted the following items at the time of initial diagnosis of AVN: (1) demographic data-age, sex, and other personal information; (2) primary clinical data, including symptoms such as pain, limp, and restricted hip function, and the interval between PFNF and AVN; and (3) primary radiographic characteristics of AVN after PFNF, including the stage of disease progression, Japanese Investigation Committee (JIC) classification system [27], and Ratliff classification [2].

The disease progression of AVN was determined according to the Association Research Circulation Osseous staging system [28]: stage I was defined as "normal radiography and computed tomography with an abnormal bone scan and/or magnetic resonance images"; stage II was defined as "sclerosis, osteolysis, or focal osteoporosis in the femoral head"; stage III was defined as "crescent sign and/or flattening of the articular surface" (stage IIIA: collapse $<2 \mathrm{~mm}$, IIIB: collapse ranging from 2 to $4 \mathrm{~mm}$, and IIIC: collapse $>4 \mathrm{~mm}$ ); and stage IV was defined by the appearance of degenerative changes (osteoarthritis, acetabular changes, or joint destruction). Types $\mathrm{A}, \mathrm{B}$, and $\mathrm{C} 1$ were assigned to groups where the necrotic area did not extend to the acetabular edge (inside coverage). Type $\mathrm{C} 2$ was assigned to groups where there was inside coverage of the necrotic area. Then, we analyzed whether the location of the necrotic area affected the prognosis. The degree of collapse was also measured by evaluating the concentric circles on both anteroposterior and lateral radiographs using ImageJ (1.52a, National Institutes of Health, USA), in reference to a previous study [29].

All the radiographic characteristics and outcomes were evaluated independently by two experienced orthopedic surgeons. If inconsistent results existed, a third surgeon participated and decided the ultimate result.

\section{Statistical analysis}

The relationships between disease progression and other clinical and radiographic factors were analyzed by independent sample $T$ tests, Chi-square tests, Fisher's exact tests, Spearman correlation test, and Mann-Whitney $U$ tests. Then, univariate and multivariate analyses were used to detect the OR (odds ratio) and adjusted OR of the factors relevant to the stage of collapse via binary logistic regression models. The variables with $P<0.05$ were considered significant. The statistical analyses were performed using the SPSS software v.22.0 (SPSS Inc., Chicago, IL, USA).

\section{Results}

\section{Systematic review}

Initially, 712 articles were obtained by searching, and two authors obtained 79 studies by reading the title and abstract. Finally, through reading the full text and performing a manual search, a total of 21 articles meeting the requirements were included in our study. The detailed process and information of the 21 included articles are shown in Fig. 1 and Table 1. Finally, 686 patients with PFNF were included. The age range of the patients was 2 to 19 years old. A total of 203 patients developed avascular necrosis, with an incidence of $29.6 \%$ (203 of 686 patients). Ratliff's classification method was used in 19 articles to describe the degree of osteonecrosis, and the classification of osteonecrosis after femoral neck fracture was recorded in 178 pediatric patients, with type I necrosis accounting for 58.4\% (104 of 178), type II accounting for $25.3 \%$ (45 of 178), and type III accounting for $16.3 \%$ (29 of 178). Ratliff's assessment was used in 13 articles to evaluate the final prognosis of patients from both clinical and imaging perspectives. The final prognosis of osteonecrosis after femoral neck fracture in 147 children was recorded, with $11.6 \%$ (17 of 147) having a satisfactory prognosis and $88.4 \%$ (130 of 147) having an unsatisfactory prognosis.

\section{Retrospective study}

A total of 155 children and adolescents (155 hips) were diagnosed with AVN after PFNF. In addition, 115 patients had complete medical records or radiographic data. The demographic message of these patients is summarized in Table 3.The mean interval between AVN and PFNF was $13.7 \pm 9.5$ months. In detail, 71 of 115 (61.7\%) cases of AVN were detected in the first year after PFNF, while $32(27.8 \%)$ and $12(10.4 \%)$ were detected within and after the second year, respectively. At the time of diagnosis, 68 were symptomatic patients. The most common symptoms were varying degrees of hip pain, limp, and restricted hip function.

According to the anteroposterior X-ray results and the ACRO staging system, 40 (34.8\%) and 75 (65.2\%) hips remained with stages II (non-collapsed stage) and III (collapsed stage) disease, respectively; 34 hips collapsed by less than $2 \mathrm{~mm}$ (stage IIIA), 16 hips collapsed in a range from 2 to $4 \mathrm{~mm}$ (stage IIIB), and 25 hips collapsed by more than $4 \mathrm{~mm}$ (stage IIIC). Using Ratliff's classification, the type III hips (4 hips) were much less than the type I (50 hips) and type II (61 hips). Regarding the JIC 




classification, the type $\mathrm{C} 2$ accounted the most number of included hips (53.9\%), followed by the type $\mathrm{C} 1$ (34.8\%), and type $\mathrm{A} / \mathrm{B}$ accounted the least part (11.3\%).

The relationships between disease progression, which was defined by ARCO stage, and other clinical and radiographic factors were analyzed (Table 4). Hip symptoms likely indicated a disease progression since the percentage of stage III (collapsed) hips in symptomatic hips $(85.3 \%)$ is significantly higher than that in asymptomatic hips (36.2\%) (Fig. 2). Furthermore, the JIC classification and Ratliff's classification showed a significant relationship with disease progression (Fig. 3). In detail, the type C2 hips showed the highest risk of collapse progression since $82.3 \%$ of them had progressed to femoral head collapse, followed by the type $\mathrm{C} 1$ hips (57.5\%), and the type A/B showed the lowest risk (7.7\%). Not surprisingly, $86 \%$ of hips with type I necrosis, which represented the highest risk, were in the collapsed stage, followed by hips with types II (52\%) and III (0\%) necrosis.

Unadjusted univariate analysis was used to detect the odds ratio (OR). Disease stage presented no significant correlation with age $(\mathrm{OR}=0.91,95 \% \mathrm{CI}=0.72-1.16)$, sex $(\mathrm{OR}=0.86,95 \% \mathrm{CI}=0.37-1.96)$, and interval between fracture and $\mathrm{AVN}$ diagnosis $(\mathrm{OR}=1.49,95 \% \mathrm{CI}=$ 0.81-2.73), however, a significant relation with symptom $(\mathrm{OR}=10.24,95 \% \mathrm{CI}=4.17-25.1), \mathrm{JIC}$ classification $(\mathrm{OR}$ $=5.08,95 \% \mathrm{CI}=2.54-10.12)$, and Ratliff classification $(\mathrm{OR}=0.15,95 \% \mathrm{CI}=0.06-0.37)$. Then, multivariate analysis was used to detect the adjusted OR of the factors relevant to the stage of collapse. Symptomatic patients $(\mathrm{OR}=6.25,95 \% \mathrm{CI}=2.39-16.36)$ and $\mathrm{JIC}$ classification $(\mathrm{OR}=3.41,95 \% \mathrm{CI}=1.62-7.17)$ showed a strong relationship with the stage of collapse in AVN. 
Table 3 Demographic, clinical and radiographic characteristics of AVN after PFNF

\begin{tabular}{|c|c|c|c|c|}
\hline & Total & Non-collapsed stage & Collapsed stage & $p$ value \\
\hline \multicolumn{5}{|l|}{ Demographic parameters } \\
\hline Age (mean $\pm S D$, years) & $13.6 \pm 2.0$ & $13.6 \pm 2.1$ & $13.5 \pm 1.2$ & $0.89^{*}$ \\
\hline $\operatorname{Sex}(n, \%)$ & & & & $0.72^{* *}$ \\
\hline Male & $78(67.8)$ & $28(70.0)$ & $50(66.7)$ & \\
\hline Female & $37(32.2)$ & $12(30.0)$ & $25(33.3)$ & \\
\hline Side $(n, \%)$ & & & & $<0.01^{* *}$ \\
\hline Left & $51(44.3)$ & $11(27.5)$ & $40(53.3)$ & \\
\hline Right & $64(55.7)$ & $29(72.5)$ & $35(46.7)$ & \\
\hline \multicolumn{5}{|l|}{ Clinical characteristics } \\
\hline $\begin{array}{l}\text { Interval between fracture and AVN } \\
\text { diagnosis (mean } \pm \mathrm{SD} \text {, months) }\end{array}$ & $13.7 \pm 9.5$ & $15.1 \pm 9.8$ & $11.2 \pm 8.5$ & $0.04^{*}$ \\
\hline \multicolumn{5}{|l|}{ Symptomatic $(n, \%)$} \\
\hline Yes & $68(59.1)$ & $10(25.0)$ & $58(77.3)$ & $<0.01^{* *}$ \\
\hline No & $47(40.9)$ & $30(75.0)$ & $17(22.7)$ & \\
\hline Hip pain $(n, \%)$ & & & & $<0.01^{* *}$ \\
\hline Yes & $63(54.8)$ & $10(25.0)$ & $53(70.7)$ & \\
\hline No & $52(45.2)$ & $30(75.0)$ & $22(29.3)$ & \\
\hline $\operatorname{Limp}(n, \%)$ & & & & $<0.01^{* *}$ \\
\hline Yes & $58(50.4)$ & $6(15.0)$ & $52(69.3)$ & \\
\hline No & 57 (49.6) & $34(85.0)$ & $23(30.7)$ & \\
\hline Restricted hip function & & & & $<0.01^{* * *}$ \\
\hline Yes & $34(29.6)$ & $1(2.5)$ & $33(56.0)$ & \\
\hline No & $81(70.4)$ & $39(97.5)$ & $42(44.0)$ & \\
\hline \multicolumn{5}{|l|}{ Radiographic characteristics } \\
\hline Ratliff classification of AVN $(n, \%)$ & & & & $<0.01^{* * * *}$ \\
\hline Type I & $50(43.5)$ & $7(17.5)$ & $43(43.5)$ & \\
\hline Type II & $61(53.0)$ & $29(72.5)$ & $32(53.0)$ & \\
\hline Type III & $4(3.5)$ & $4(10.0)$ & $0(0)$ & \\
\hline JIC classification of AVN $(n, \%)$ & & & & $<0.01^{* * * *}$ \\
\hline $\mathrm{A} / \mathrm{B}$ & $13(11.3)$ & $12(30.0)$ & $1(1.3)$ & \\
\hline C1 & $40(34.8)$ & $17(42.5)$ & $23(30.7)$ & \\
\hline $\mathrm{C} 2$ & $62(53.9)$ & $11(27.5)$ & $51(68.0)$ & \\
\hline \multicolumn{5}{|l|}{ ARCO stage $(n, \%)$} \\
\hline$\|$ & $40(34.8)$ & & & \\
\hline$\| \mathrm{A}$ & $34(29.6)$ & & & \\
\hline$\| \mathrm{IIB}$ & $16(13.9)$ & & & \\
\hline IIIC & $25(21.7)$ & & & \\
\hline
\end{tabular}

ARCO Association Research Circulation Osseous, AVN avascular necrosis, JIC Japanese Investigation Committee *Independent sample $t$ test

${ }^{* *}$ Chi-square test

***Fisher's exact test

****Mann-Whitney $U$ test

\section{Discussion}

A classification system and a set of criteria for clinical and radiographic assessment were first reported by Ratliff and his colleagues in the 1960s, portraying AVN as a severe complication secondary to pediatric femoral neck fractures [2]. Since then, numerous studies have adapted Ratliff's methods described above to classify AVN after PFNF and to assess outcomes. However, 
Table 4 Relationship between disease characteristics and progression analyzed by Binary logistic regression models

\begin{tabular}{|c|c|c|c|c|c|c|c|}
\hline \multirow[t]{2}{*}{ Parameters } & \multicolumn{5}{|c|}{ ARCO stage } & \multirow{2}{*}{$\begin{array}{l}\text { OR }(95 \% \mathrm{Cl}) \text { of } \\
\text { collapsed stage }\end{array}$} & \multirow{2}{*}{$\begin{array}{l}\text { Adjusted-OR } \\
(95 \% \mathrm{Cl}) \text { of } \\
\text { collapsed stage * }\end{array}$} \\
\hline & Total & II & IIIA & IIIB & $\overline{\text { IIIC }}$ & & \\
\hline Age (years, $n$ ) & & & & & & $0.91(0.72-1.16)$ & \\
\hline$\leq 11$ & 17 & 4 & 5 & 3 & 5 & & \\
\hline 12 & 13 & 3 & 4 & 2 & 4 & & \\
\hline 13 & 20 & 10 & 4 & 2 & 4 & & \\
\hline 14 & 25 & 9 & 9 & 2 & 5 & & \\
\hline 15 & 24 & 8 & 9 & 2 & 5 & & \\
\hline$\geq 16$ & 16 & 6 & 3 & 5 & 2 & & \\
\hline $\operatorname{Sex}(n)$ & & & & & & $0.86(0.37-1.96)$ & \\
\hline Male & 78 & 28 & 25 & 10 & 15 & & \\
\hline Female & 37 & 12 & 9 & 6 & 10 & & \\
\hline Symptomatic (n) & & & & & & $10.24(4.17-25.1)^{* *}$ & $6.25(2.39-16.36)$ ** \\
\hline No & 47 & 30 & 12 & 3 & 2 & & \\
\hline Yes & 68 & 10 & 22 & 13 & 23 & & \\
\hline $\begin{array}{l}\text { Interval between fracture and } \\
\text { AVN diagnosis }(n)\end{array}$ & & & & & & $1.49(0.81-2.73)$ & \\
\hline Within 1 year & 71 & 27 & 20 & 11 & 13 & & \\
\hline 1 to 2 years & 32 & 11 & 10 & 4 & 7 & & \\
\hline More than 2 years & 12 & 2 & 4 & 1 & 5 & & \\
\hline JIC classification ( $n$ ) & & & & & & $5.08(2.54-10.12){ }^{* *}$ & $3.41(1.62-7.17) * *$ \\
\hline$A / B$ & 13 & 12 & 1 & 0 & 0 & & \\
\hline $\mathrm{C} 1$ & 40 & 17 & 21 & 1 & 1 & & \\
\hline $\mathrm{C} 2$ & 62 & 11 & 12 & 15 & 24 & & \\
\hline Ratliff classification ( $n$ ) & & & & & & $0.15(0.06-0.37) * *$ & \\
\hline । & 50 & 7 & 8 & 12 & 23 & & \\
\hline$\|$ & 61 & 29 & 26 & 4 & 2 & & \\
\hline III & 4 & 4 & 0 & 0 & 0 & & \\
\hline
\end{tabular}

ARCO Association Research Circulation Osseous, AVN avascular necrosis, JIC Japanese Investigation Committee *Multivariate analysis with method of "Forward LR"

${ }^{* *} p<0.05$

owing to the limitation of sample size, the specific characteristics of AVN after PFNF remain unknown. This study is the first, to our knowledge, to address these deficiencies through a cross-sectional study of diagnostic data from 115 patients and a systematic review.

The best characteristic for predicting AVN after PFNF was a rapid disease course with a high risk of femoral head collapse and poorer prognosis. As the first step, we identified similar data for a systematic review. Among the 21 studies enrolled, 19 adopted Ratliff's classification and included 178 hips, with types I, II, and III necrosis $58.4 \%, 25.3 \%$, and $16.3 \%$, respectively, and the final prognosis of AVN after PFNF in 147 children was recorded, 88.4\% having an unsatisfactory prognosis. Among the 115 hips from our clinical data, $43.5 \%, 53.0 \%$, and $3.5 \%$ were defined as having types I, II, and III necrosis, respectively, according to Ratliff's classification. A systematic review and our clinical data indicated a dominant proportion of extensively involved AVN lesions after PFNF, inevitably pointing to the rapid progression of the disease. As Ratliff reported [2], patients with type I and type II AVN are generally predisposed to a poor prognosis, often with progressive femoral head collapse and hip subluxation and, ultimately, hip degeneration. No hippreserving treatments with confirmed therapeutic effects except for arthrodesis or arthroplasty have been recommended for these severe conditions [21, 30]. According to the mainstream explanations of the published literature, this poor condition can primarily be ascribed to the high-energy primary trauma and the obstruction of 

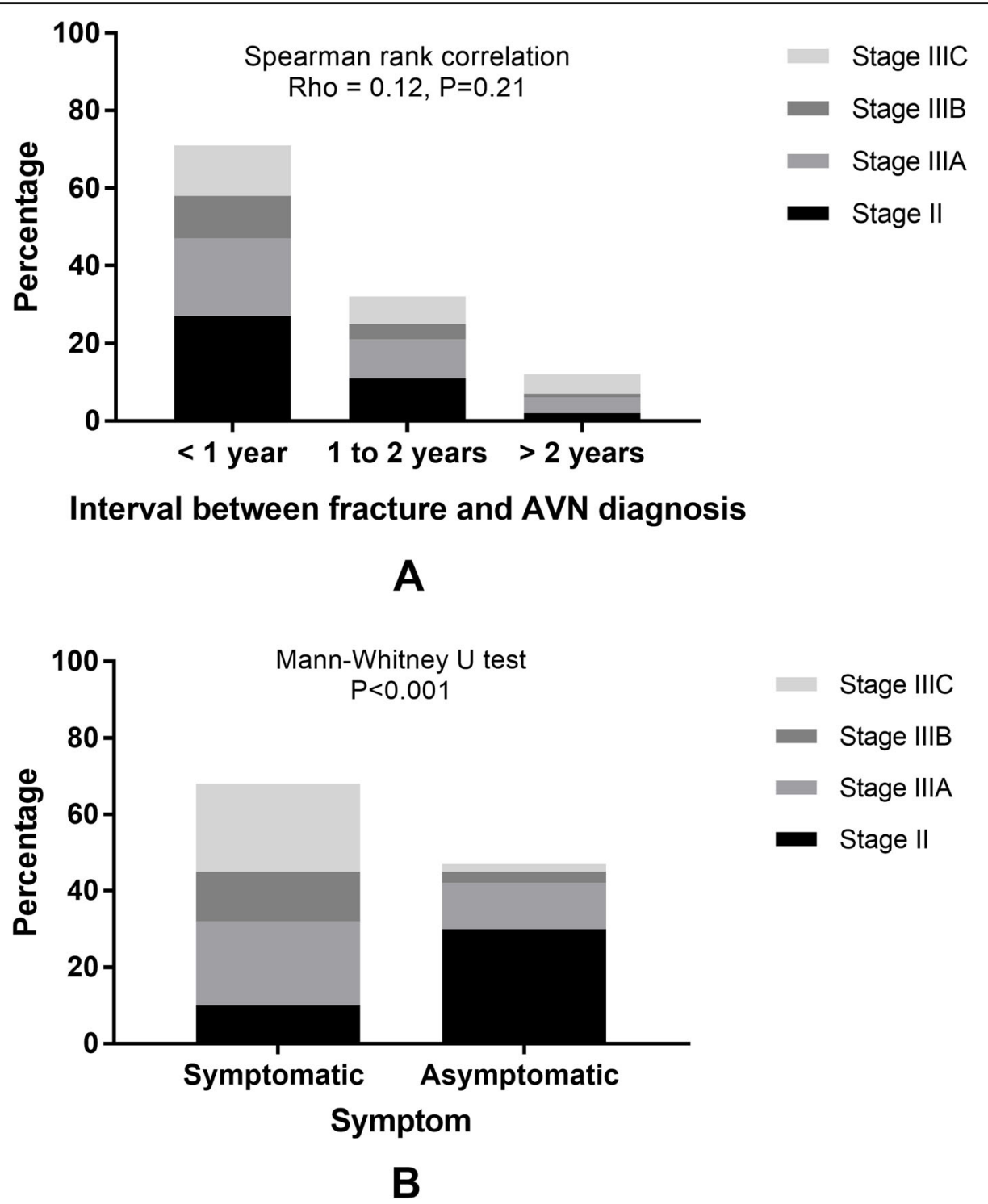

Fig. 2 The relationship between clinical symptoms and disease progression

compensatory blood supplies induced by immature epiphyseal plates in these populations $[1,2,31]$. Similarly, Legg-Calve-Perthes disease is also a common etiology of childhood osteonecrosis, usually with extensive and severe involvement of the epiphysis [32, 33].

Symptoms, as one of the recognized prognostic factors of disease progression in most types of AVN, showed a significant relationship with the ARCO stage in this study [26, 34, 35]. According to our data, hip symptoms, such as hip pain, limp, and restricted hip function, were recorded in 68 of 115 cases, $85.3 \%$ of which had progressed to femoral head collapse. In contrast, 47 asymptomatic patients were diagnosed via routine follow-up, and only $36.2 \%$ of them had already progressed to the collapsed stage. These data likely suggest symptoms as a risk factor for femoral head collapse. On the other hand, the interval between hip fracture and AVN diagnosis was recorded. The average duration was 13.7 months, which was similar to a previous report [36]. Considering that $61.7 \%$ and $27.8 \%$ of AVN cases were diagnosed in the first and second years after a hip injury, a prolonged follow-up of 2 years was indispensable for this population, even for asymptomatic cases.

As a cross-sectional study, our data revealed a potential relationship between disease progression and necrotic involvement. We found that at the time of diagnosis, 43 of 50 (86\%) hips with type I necrosis and 32 of 61 (52\%) with type II necrosis had already progressed to femoral head collapse, and there was no 


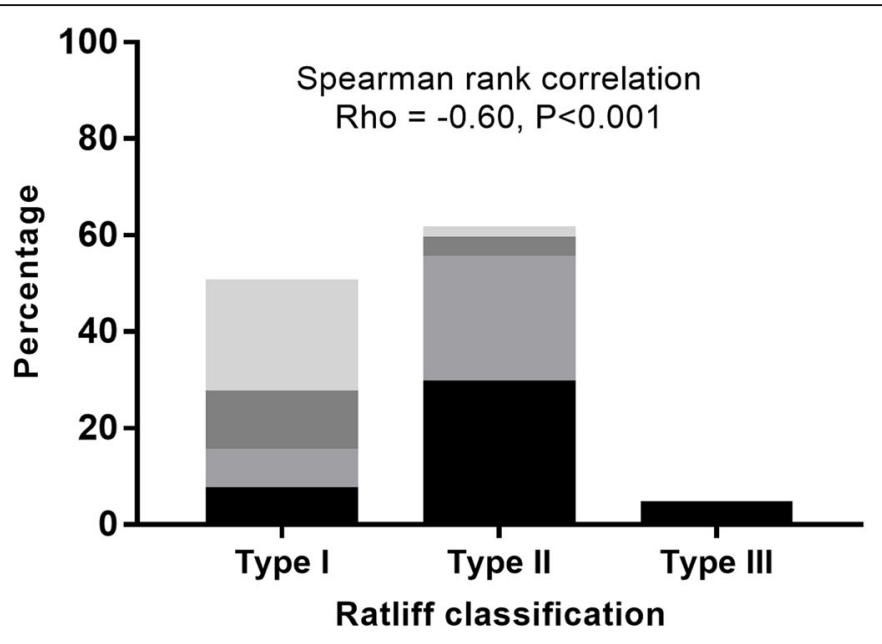

Stage IIIC

Stage IIIB

Stage IIIA

Stage II

A

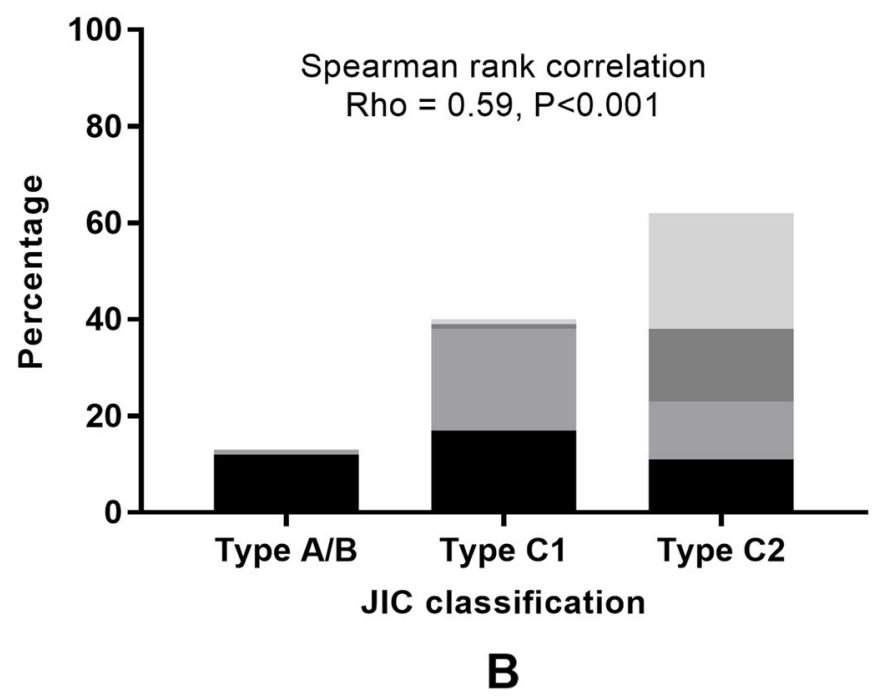

Stage IIIC

Stage IIIB

Stage IIIA

Stage II

Fig. 3 The relationship between JIC classification and Ratliff's classification and disease progression

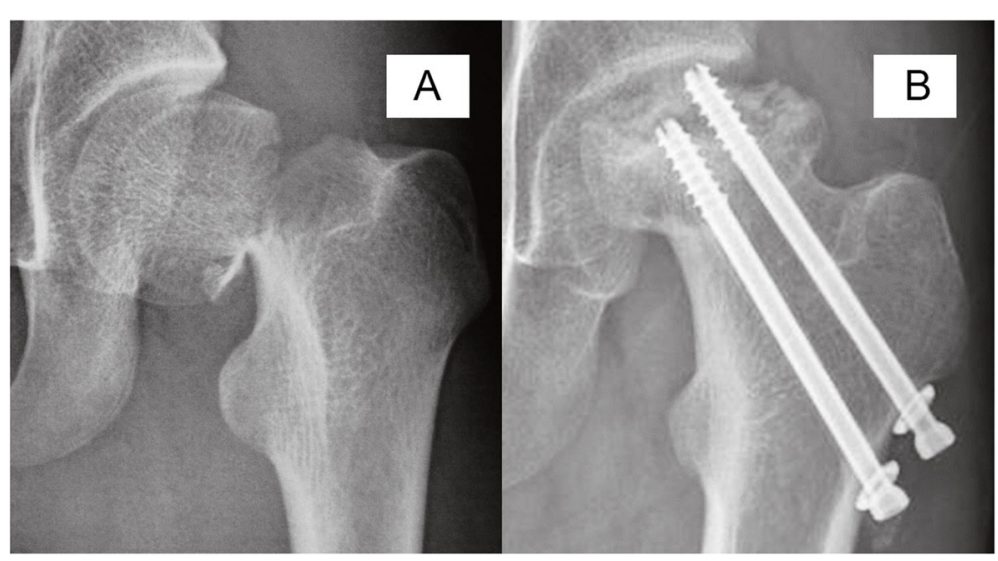

Fig. 4 The anteroposterior radiographs of Ratliff type I avascular necrosis after pediatric femoral neck fracture. Femoral neck fracture occurred at age of 14 years (a) and avascular necrosis was diagnosed 16 months later (b), type C2 according JIC classification, presenting severe femoral head and hip subluxation 


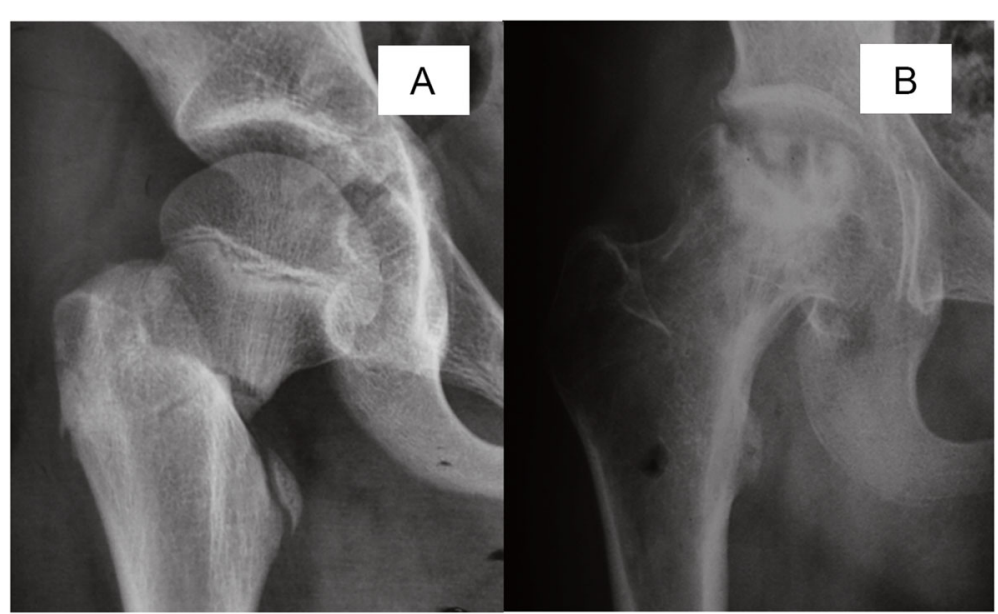

Fig. 5 The anteroposterior radiographs of Ratliff type I avascular necrosis after pediatric femoral neck fracture. Femoral neck fracture occurred at age of 12 years (a) and avascular necrosis were diagnosed 8 months later (b), and JIC type C2, presenting collapsed femoral head

collapsed hip in type III, indicating that in the type I hips appear the higher risk of collapse compared with other two types. The influence of the location of the lesion is not demonstrated in the Ratliff classification. Therefore, we attempted to use the JIC classification as a complement to address the deficiency of Ratliff's classification, principally as a result of setting a subclassification of Ratliff's type II AVN. It is widely accepted that the JIC classification is a practical method for predicting the risk of femoral head collapse in adult necrosis of the femoral head with confirmed intra- and interobserver concordance [37]. There is no doubt that all the cases of Ratliff's type I AVN were classified as JIC stage C2 (Fig. 4); however, the definition of Ratliff's type II AVN is vague. The partial involvement of necrosis can also be classified as JIC stage C1 or C2 (Figs. 5 and 6). Both of these conditions involve the lateral part of the femoral head; however, in the latter stage, AVN encroaches extensively beyond the lateral margin of the acetabulum and induces the highest risk of femoral head collapse. In the current study, at the time of AVN diagnosis, correlation analysis indicated a significant positive relationship between disease stage and JIC classification. In detail, $82.3 \%$ of type $\mathrm{C} 2$ hips and $57.5 \%$ of type $\mathrm{C} 1$ hips progressed to femoral head collapse. Further multivariate logistic analysis also demonstrated that the JIC classification showed a stronger correlation with femoral head collapse than did Ratliff's classification.

Several limitations still exist. First and foremost, although this investigation was the first, to our knowledge, to include the largest sample size of enrolled patients to describe the radiographic and clinical characteristics of AVN after PFNF via a cross-sectional study, patient selection bias should not be neglected in a retrospective

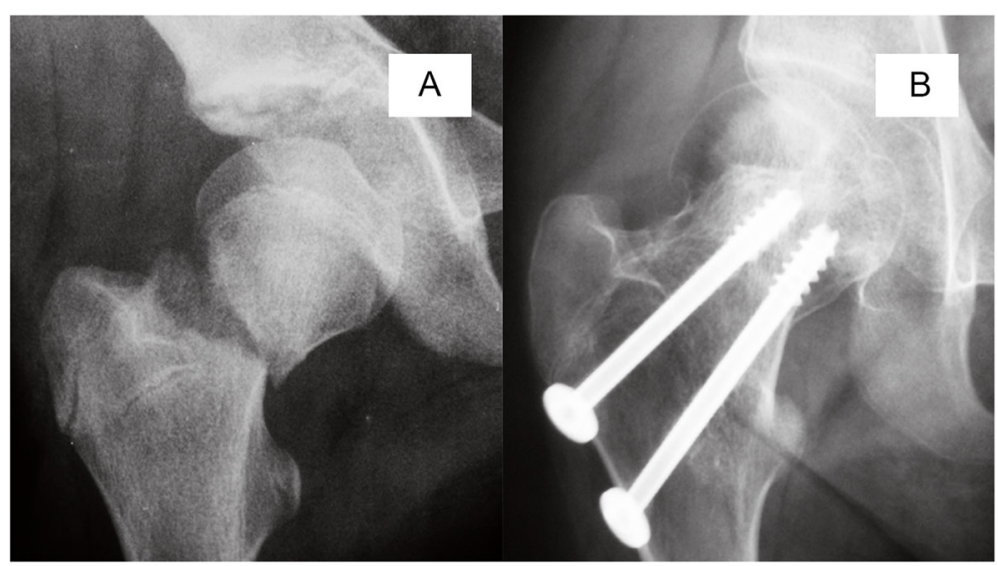

Fig. 6 The anteroposterior radiographs of Ratliff type II avascular necrosis after pediatric femoral neck fracture. Femoral neck fracture occurred at age of 10 years (a) and avascular necrosis were diagnosed 5 months later (b), and JIC type C1, presenting non-collapsed femoral head 
study. Secondly, as a retrospective study, we failed to record or analyze the factors related to primary hip fracture in all patients, such as the classification, degree of displacement, methods of reduction, and types of internal fixation. Lastly, as a cross-sectional study, although our data related radiographic and clinical characteristics to disease progression, we could not confirm the prognostic value of these factors. Further prospective multicenter control trials or case series with advanced radiologic technology are suggested to confirm the results.

\section{Conclusions}

In summary, our recent study first identified the clinical and radiographic characteristics of AVN after PFNF. According to our results from a systematic review and cross-sectional study, we believe that the most prominent feature of AVN after PFNF is the tendency toward extensive necrotic lesions, which predisposes this population to a poor prognosis. More than half of the patients had progressed to an advanced stage when the diagnosis of AVN was confirmed, usually around the first year after PFNF. And the symptoms and the JIC classification are the other two risk factors of collapse progression.

\section{Supplementary Information}

The online version contains supplementary material available at https://doi. org/10.1186/s13018-020-02037-2.

Additional file 1. Search strategy.

Additional file 2. IHE's quality appraisal checklist for assessing caseseries studies.

\section{Abbreviations}

PFNFs: Pediatric femoral neck fractures; AVN: Avascular necrosis; IHE: Institute of Health Economics; JIC: Japanese Investigation Committee;

ARCO: Association Research Circulation Osseous; OR: Odds ratio

\section{Acknowledgements}

I would like to thank professor Wei He and his team members for their guidance and support for this article.

\section{Authors' contributions}

Conceptualization: Pengfei Xin, Ziqi Li; literature review and search: Pengfei Xin, Ziqi Li; data collection: YongGang Tu, Zhinan Hong, Ziqi Li; data analysis and interpretation: Fan Yang, Fengxiang Pang; manuscript preparation and editing: Pengfei Xin, Ziqi Li; supervision: Wei He, Qiushi Wei. The author(s) read and approved the final manuscript.

\section{Funding}

The article received financial support from the National Natural Science Foundation of China (No. 81873327 and No. 81904226).

\section{Availability of data and materials}

The authors declare that all the data supporting the findings of this study are available within the article and its supplementary information files.
Consent for publication

Not applicable

\section{Competing interests}

The authors declare that they have no competing interests.

\section{Author details}

${ }^{1}$ The First Clinical Medical School, Guangzhou University of Chinese Medicine, Jichang Road 12\#, District Baiyun, Guangzhou, Guangdong, China. ${ }^{2}$ Laboratory of Orthopaedics \& Traumatology, Lingnan Medical Research Center, Guangzhou University of Chinese Medicine, Guangzhou, China. ${ }^{3}$ Department of Orthopaedics, Dongguan Eastern Central Hospital, Dongguan, Guangdong, China. ${ }^{4}$ Department of Joint Surgery, The Third Affiliated Hospital of Guangzhou University of Chinese Medicine, Guangzhou 510405, China

Received: 31 August 2020 Accepted: 28 October 2020

Published online: 11 November 2020

\section{References}

1. Ratliff $\mathrm{AH}$. Avascular necrosis of the head of the femur, after fractures of the femoral neck in children, and Perthes' disease. Proc R Soc Med. 1962;55: 504-5.

2. Ratliff $\mathrm{AH}$. Fractures of the neck of the femur in children. J Bone Joint Surg (Br). 1962;44-B:528-42

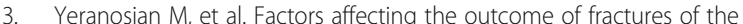
femoral neck in children and adolescents: a systematic review. Bone Joint J. 2013;95-B(1):135-42.

4. Wang WT, et al. Risk factors for the development of avascular necrosis after femoral neck fractures in children: a review of 239 cases. Bone Joint J. 2019; 101-B(9):1160-7.

5. Stone JD, et al. Open reduction of pediatric femoral neck fractures reduces osteonecrosis risk. Orthopedics. 2015:38(11):E983-90.

6. Panigrahi $R$, et al. Treatment analysis of paediatric femoral neck fractures: a prospective multicenter therapeutic study in Indian scenario. Int Orthop. 2015;39(6):1121-7

7. Bukva B, et al. Femoral neck fractures in children and the role of early hip decompression in final outcome. Injury Int J Care Injured. 2015;46:S44-7.

8. Hajdu $S$, et al. Fractures of the head and neck of the femur in children: an outcome study. Int Orthop. 2011;35(6):883-8.

9. Bali $\mathrm{K}$, et al. Pediatric femoral neck fractures: our 10 years of experience. Clin Orthop Surg. 2011;3(4):302-8

10. Nayeemuddin $\mathrm{M}$, et al. Complication rate after operative treatment of paediatric femoral neck fractures. J Pediatr Orthop B. 2009:18(6):314-9.

11. Inan $U$, Kose N, Omeroglu H. Pediatric femur neck fractures: a retrospective analysis of 39 hips. J Child Orthop. 2009:3(4):259-64.

12. Varshney MK, et al. Functional and radiological outcome after delayed fixation of femoral neck fractures in pediatric patients. J Orthop Traumatol. 2009;10(4):211-6.

13. Dhammi IK, Singh S, Jain AK. Displaced femoral neck fracture in children and adolescents: closed versus open reduction--a preliminary study. J Orthop Sci. 2005;10(2):173-9.

14. Togrul $E$, et al. Fractures of the femoral neck in children: long-term followup in 62 hip fractures. Injury Int J Care Injured. 2005;36(1):123-30.

15. Flynn JM, et al. Displaced fractures of the hip in children. Management by early operation and immobilisation in a hip spica cast. J Bone Joint Surg (Br). 2002;84(1):108-12

16. Bagatur AE, Zorer G. Complications associated with surgically treated hip fractures in children. J Pediatr Orthop B. 2002:11(3):219-28.

17. Mirdad T. Fractures of the neck of femur in children: an experience at the Aseer Central Hospital, Abha, Saudi Arabia. Injury Int J Care Injured. 2002; 33(9):823-7.

18. Morsy HA. Complications of fracture of the neck of the femur in children. A long-term follow-up study. Injury Int J Care Injured. 2001;32(1):45-51.

19. $\mathrm{Ng} \mathrm{GP,} \mathrm{Cole} \mathrm{WG.} \mathrm{Effect} \mathrm{of} \mathrm{early} \mathrm{hip} \mathrm{decompression} \mathrm{on} \mathrm{the} \mathrm{frequency} \mathrm{of}$ avascular necrosis in children with fractures of the neck of the femur. Injury. 1996;27(6):419-21

20. Forlin $\mathrm{E}_{\text {, et }}$ al. Complications associated with fracture of the neck of the femur in children. J Pediatr Orthop. 1992;12(4):503-9.

21. Canale ST, Bourland WL. Fracture of the neck and intertrochanteric region of the femur in children. J Bone Joint Surg Am. 1977;59(4):431-43. 
22. Chong KC, Chacha PB, Lee BT. Fractures of the neck of the femur in childhood and adolescence. Injury. 1975;7(2):111-9.

23. Zolczer L, et al. Fractures of the femoral neck in adolescence. Injury. 1972; 4(1):41-6.

24. Lam SF. Fractures of the neck of the femur in children. The Journal of bone and joint surgery. Am Vol. 1971;53(6):1165-79.

25. Mont MA, et al. Nontraumatic osteonecrosis of the femoral head: where do we stand today? A ten-year update. J Bone Joint Surg Am. 2015;97(19): 1604-27.

26. Mont MA, et al. The natural history of untreated asymptomatic osteonecrosis of the femoral head: a systematic literature review. J Bone Joint Surg Am. 2010;92(12):2165-70.

27. Sugano $\mathrm{N}$, et al. The 2001 revised criteria for diagnosis, classification, and staging of idiopathic osteonecrosis of the femoral head. J Orthop Sci. 2002; 7(5):601-5.

28. Sultan AA, et al. Classification systems of hip osteonecrosis: an updated review. Int Orthop. 2019;43(5):1089-95.

29. Kubo Y, et al. The effect of the anterior boundary of necrotic lesion on the occurrence of collapse in osteonecrosis of the femoral head. Int Orthop. 2018;42(7):1449-55.

30. Kim HKW, et al. Childhood femoral head osteonecrosis. Clin Rev Bone Miner Metab. 2011;9(1):2-12.

31. Trueta J. The normal vascular anatomy of the human femoral head during growth; 1957

32. Canavese F, Dimeglio A. Perthes' disease: prognosis in children under six years of age. J Bone Joint Surg (Br). 2008;90(7):940-5.

33. Wiig $\mathrm{O}$, Terjesen $\mathrm{T}$, Svenningsen $\mathrm{S}$. Inter-observer reliability of the Stulberg classification in the assessment of Perthes disease. J Child Orthop. 2007;1 (2):101-5.

34. Nam KW, et al. Fate of untreated asymptomatic osteonecrosis of the femoral head. J Bone Joint Surg Am. 2008;90(3):477-84.

35. Hatanaka $\mathrm{H}$, et al. Differences in magnetic resonance findings between symptomatic and asymptomatic pre-collapse osteonecrosis of the femoral head. Eur J Radiol. 2019;112:1-6.

36. Spence $D$, et al. Osteonecrosis after femoral neck fractures in children and adolescents: analysis of risk factors. J Pediatr Orthop. 2016;36(2):111-6.

37. Takashima $\mathrm{K}$, et al. Which classification system is most useful for classifying osteonecrosis of the femoral head? Clin Orthop Relat Res. 2018;476(6):1240-9.

\section{Publisher's Note}

Springer Nature remains neutral with regard to jurisdictional claims in published maps and institutional affiliations.

Ready to submit your research? Choose BMC and benefit from:

- fast, convenient online submission

- thorough peer review by experienced researchers in your field

- rapid publication on acceptance

- support for research data, including large and complex data types

- gold Open Access which fosters wider collaboration and increased citations

- maximum visibility for your research: over $100 \mathrm{M}$ website views per year

At $\mathrm{BMC}$, research is always in progress.

Learn more biomedcentral.com/submissions 